\title{
CYP2D6 gene polymorphisms in Brazilian patients with breast cancer treated with adjuvant tamoxifen and its association with disease recurrence
}

\author{
MARIELLA DE AMEIDA MELO ${ }^{1,2}$, RODRIGO JOSÉ DE VASCONCELOS-VALENÇA ${ }^{1,2}$, \\ FIDELIS MANES NETO ${ }^{2}$, RAFAEL SOARES BORGES ${ }^{3}$, DANYLO RAFHAEL COSTA-SILVA ${ }^{1}$, \\ MARIA DA CONCEIÇÃO BARROS-OLIVEIRA ${ }^{1}$, UMBELINA SOARES BORGES ${ }^{1}$, \\ AIRLANE PEREIRA ALENCAR ${ }^{4}$, VLADIMIR COSTA SILVA ${ }^{5}$ and BENEDITO BORGES DA SILVA ${ }^{1}$ \\ ${ }^{1}$ Department of Gynecology, Federal University of Piauí, Health Sciences Center, Teresina, PI 64001-020; \\ ${ }^{2}$ Department of Oncology, São Marcos Hospital, Teresina, PI 64001-280; ${ }^{3}$ Department of Mastology, \\ Getulio Vargas Hospital, Federal University of Piauí, Teresina, PI 64001-020; ${ }^{4}$ Department of Statistics, \\ State University of São Paulo, São Paulo, SP 05508-900; ${ }^{5}$ Department of Molecular Biology, \\ Natan Portella Hospital, Federal University of Piaui, Teresina, PI 64001-450, Brazil
}

Received July 14, 2016; Accepted September 20, 2016

DOI: $10.3892 /$ br.2016.771

\begin{abstract}
At present, there is controversy regarding the efficacy of tamoxifen in breast cancer patients who are carriers of cytochrome P450 2D6 (CYP2D6) gene polymorphisms, in terms of recurrence and overall survival. Thus, the aim of the present study was to investigate the association of the CYP2D6 $* 4, * 10$ and $* 17$ gene polymorphisms with breast cancer recurrence in a Brazilian population. The cohort comprised 40 receptor-positive breast cancer patients without recurrence and 40 with distant recurrence. A 3-ml sample of peripheral blood was collected from each patient to determine the presence of the $* 4, * 10$ and $* 17$ single nucleotide polymorphisms of the CYP2D6 gene by quantitative polymerase chain reaction analysis. There was no statistically significant difference between the two groups regarding the polymorphism frequency $(\mathrm{P}=0.246)$. The results revealed that intermediate metabolizers occurred in $5 \%$ of patients without recurrence and in $15 \%$ of those with distant recurrence. Poor metabolizers occurred in only 1 patient $(2.5 \%)$ per group, and there was no significant difference between the groups $(\mathrm{P}=0.789)$. The present study concluded that the CYP2D6 gene polymorphism
\end{abstract}

Correspondence to: Professor Benedito Borges da Silva, Department of Gynecology, Federal University of Piauí, Health Sciences Center, 2280 Frei Serafim Avenue, Teresina, PI 64001-020, Brazil

E-mail: beneditoborges@globo.com

Key words: breast cancer, cytochrome P450 2D6 gene, polymorphism, tamoxifen, recurrence in women with hormone-sensitive breast cancer treated with tamoxifen was not associated with disease recurrence.

\section{Introduction}

Breast cancer is the most common type of cancer in women in Western countries (1). Furthermore, it is the second most frequent type of malignancy in women worldwide after non-melanoma skin cancer. For the year 2012, >1.6 million new cases and a breast cancer-associated mortality rate of 522,000 have been estimated (2). In Brazil, breast cancer is the most common type of cancer in women, its incidence shows yearly increases and the National Institute of Cancer estimated that 57,960 new cases of breast cancer will occur in the year 2016. However, due to the relatively low aggressiveness of the disease and the efficacy of available treatments, the prognosis of breast cancer patients is good with a mean 5-year survival rate of $61 \%$ (3).

Breast cancer treatment is multidisciplinary and the survival of affected women is associated with early diagnosis and therapeutic strategies pursued. While systemic therapy is usually applied for pre-menopausal women with early-stage breast cancer, the optimal modalities remain to be determined (4). However, almost $60 \%$ of all breast cancers in pre-menopausal women (5) and 70-80\% of post-menopausal women with breast cancer in Western countries are estrogen receptor (ER)-positive and therefore eligible for adjuvant endocrine therapy (6).

Tamoxifen, a first-generation selective ER modulator, is currently the most widely used endocrine treatment breast cancer worldwide. It has anti-estrogenic action and is used for adjuvant treatment of hormone-sensitive breast cancer, as well as for chemoprevention in women with a high risk of breast cancer (7), although aromatase inhibitors are generally preferred for post-menopausal patients (8). 
Tamoxifen is a prodrug that is extensively metabolized in the liver by the cytochrome P450 2D6 (CYP2D6) enzyme into its most pharmacologically active metabolites, endoxifen and 4-hydroxitamoxifen (9). These metabolites bind to ERs with an affinity 30-100-fold of that of tamoxifen (10). The CYP2D6 gene that encodes this enzyme is highly polymorphic and varies among different genotypes and populations. It has been established that a number of its genetic variants are deprived of any enzymatic activity, resulting in low levels of endoxifen, its main metabolite, resulting in a lack of response to tamoxifen with unfavorable patient prognosis (11).

To date, $>100$ alleles have been described for the CYP2D6 gene, which are stratified into alleles of null, intermediate, normal and ultra-rapid enzymatic activity. Variant $* 4$ is the most important null allelic variant responsible for abolishing enzymatic activity and a poor metabolism (PM), while the $* 10$ and *17 variants are responsible for a severe decrease in enzymatic activity and intermediate metabolism(IM). The most important allelic variants are $* 4, * 10$ and $* 17$, found in $25 \%$ of Caucasians, $38-70 \%$ of Asians and $35 \%$ of Africans (12). The association of CYP2D6 gene polymorphisms with the efficacy of tamoxifen in early-stage breast cancer patients has been assessed by numerous studies, whose results were conflicting. Certain studies have shown no alterations in the efficacy of tamoxifen in breast cancer patients carrying the CYP2D6 gene polymorphism in terms of recurrence and overall survival $(8,10,13)$, while other studies have demonstrated a significant influence of CYP2D6 gene polymorphisms on the efficacy of tamoxifen $(14,15)$. Only one previous study has evaluated the effects of CYP2D6 gene polymorphisms on the efficacy of tamoxifen in a Brazilian population (13). Thus, due to the controversies among studies on other populations and the scarcity of investigations in Brazilian populations, the present study was designed.

\section{Patients and methods}

Patients. The present study assessed 92 female patients aged 27-85 years with hormone-sensitive breast carcinoma with and without disease recurrence taking adjuvant tamoxifen, who were seen at the Department of Oncology of São Marcos Hospital (Teresina, Brazil) and the Department of Mastology of Getulio Vargas Hospital (the Federal University of Piauí, Teresina, Brazil) in March 2010 and followed up over five years until December 2015. Twelve patients were excluded from the study due to incorrect use of medication or technical problems, which precluded analysis. The Internal Review Board of the Federal University of Piauí (Teresina, Brazil) approved the protocol of the present study under the number 0311.0.045.000-11. All patients signed an informed consent form prior to enrolment. The study included reproductive-age women aged $>18$ years as well as post-menopausal women with no history of thromboembolic disease, who had been diagnosed with estrogen- and/or progesterone-positive and Her2-negative invasive carcinoma, a clinical stage of I-III and who had received adjuvant endocrine therapy with tamoxifen. Patients with a histological diagnosis of non-epithelial malignant tumors, those who were pregnant and those who had taken CYP2D6-inhibitory medication were not included.
Table I. Characteristics, polymorphism frequency and metabolizer phenotypes of patients without recurrence $(n=40)$ and with distant recurrence $(n=40)$ treated with adjuvant tamoxifen.

\begin{tabular}{|c|c|c|c|}
\hline Characteristics & $\begin{array}{l}\text { Without } \\
\text { recurrence, } \\
\mathrm{n}(\%)\end{array}$ & $\begin{array}{c}\text { Distant } \\
\text { recurrence, } \\
\mathrm{n}(\%)\end{array}$ & P-value \\
\hline $\begin{array}{l}\text { Age at diagnosis } \\
\text { (years) }\end{array}$ & & & 1.000 \\
\hline Mean & 50.7 & 50.2 & \\
\hline Range & $27-85$ & $29-75$ & \\
\hline \multicolumn{4}{|l|}{ Stage } \\
\hline I & $6(15)$ & $2(5)$ & 0.119 \\
\hline II & $24(60)$ & $20(50)$ & \\
\hline III & $10(25)$ & $18(45)$ & \\
\hline $\begin{array}{l}\text { Axillar lymph } \\
\text { node status }\end{array}$ & & & 0.006 \\
\hline Positive & $17(42.5)$ & $30(25.0)$ & \\
\hline Negative & $23(57.5)$ & $10(75.0)$ & \\
\hline Hormonal status & & & 1.000 \\
\hline Pre-menopausal & $25(62.5)$ & $26(65.0)$ & \\
\hline Post-menopausal & $15(37.5)$ & $14(40.0)$ & \\
\hline Alelle & & & 0.246 \\
\hline CYP2D6*1 & $26(65.0)$ & $18(45.0)$ & \\
\hline CYP2D6*4 & $3(7.5)$ & $8(20.0)$ & \\
\hline CYP2D6*10 & $7(17.5)$ & $10(25.0)$ & \\
\hline CYP2D6*17 & $4(10.0)$ & $4(10.0)$ & \\
\hline Phenotype & & & 0.492 \\
\hline $\begin{array}{l}\text { Normal } \\
\text { (homozygous) }\end{array}$ & $31(77.5)$ & $26(65.0)$ & \\
\hline $\begin{array}{l}\text { Normal } \\
\text { (heterozygous) }\end{array}$ & $6(15.0)$ & $7(17.5)$ & \\
\hline $\begin{array}{l}\text { Intermediate } \\
\text { metabolisers }\end{array}$ & $2(5.0)$ & $6(15.0)$ & \\
\hline Poor metabolisers & $1(2.5)$ & $1(2.5)$ & \\
\hline
\end{tabular}

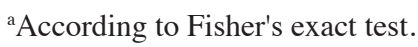

Study design. The patients enrolled in the present study were stratified into two groups of 40 patients each: Group 1 (without recurrence) and group 2 (with distant recurrence). The patients received $20 \mathrm{mg}$ tamoxifen orally per day, which was prescribed for 5 years. The groups were considered homogeneous regarding age at diagnosis, stage of the disease and hormonal status, and different regarding axillary node status, with a significantly higher rate of distant recurrence in the group with positive axilla $(\mathrm{P}=0.006$; Table I).

Sample collection and DNA extraction. From each patient, $3 \mathrm{ml}$ peripheral blood was drawn and stored in a tube containing anti-coagulant ethylenediaminetetraacetic acid. The material was stored in a sterile environment at $20^{\circ} \mathrm{C}$. For DNA extraction of leukocytes, the PureLinkGenomic ${ }^{\circledR}$ DNA Mini kit (Thermo Fisher Scientific, Inc., Waltham, MA, USA) was used according to the manufacturer's instructions. 
Table II. Identification of gene codes and SNPs used in $\operatorname{TaqMan}^{\circledR}$ assays.

\begin{tabular}{lll}
\hline Gene code & \multicolumn{1}{c}{ Product ID $^{\mathrm{a}}$} & SNP NCBI code \\
\hline CYP2D6*4 g.1846G $>$ A & C_27102431_D0 & rs3892097 \\
CYP2D6*10 g.100C $>$ T & C_11484460_40 & rs1065852 \\
CYP2D6*17 g.1023C $>$ T & C_2222771_40 & rs28371706 \\
\hline
\end{tabular}

${ }^{\mathrm{a}}$ Manufacturer, Thermo Fisher Scientific, Inc. SNP, single nucleotide polymorphism; CYP2D6, cytochrome P450 2D6; NCBI, National Center for Biotechnology Information.

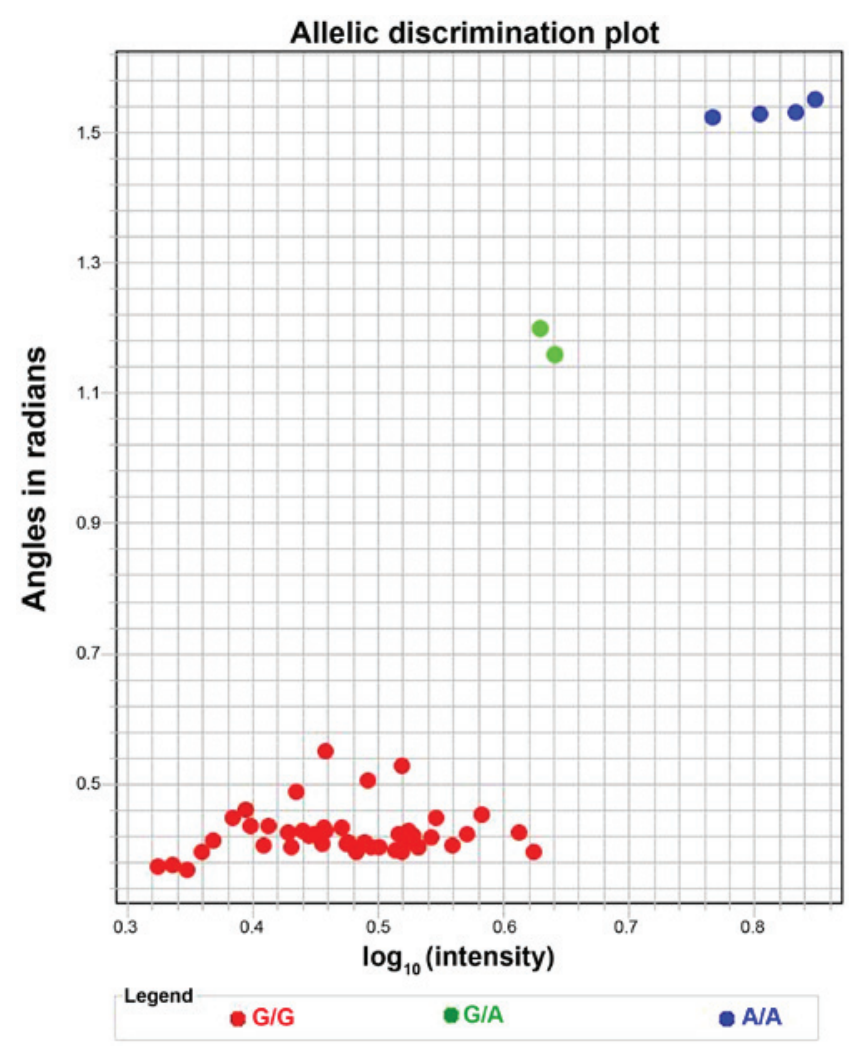

Figure 1. Plot of the polar distribution of alleles for the cytochrome P450 2D6 gene $* 17$ polymorphism in patients with distant recurrence of breast cancer. Alleles are distributed according to the amplification of their targets samples.

Quantitative polymerase chain reaction ( $q P C R)$. qPCR technique was used for analysis of the haplotypes (CYP2D6*4, $* 10$ and *17). For allele detection, TaqMan ${ }^{\circledR}$ probes (Applied Biosystems, Thermo Fisher Scientific, Inc.) were used, whose sequences were in accordance with the single nucleotide polymorphisms (SNPs) described in the database of the National Center for Biotechnology Information (Table II). These probes had a fluorophore on one end and a quencher, which is a moiety that accepts energy from the fluorophore in the form of light and dissipates it in the form of light or heat, on the other end. Reaction products were detected by fluorescence generated after exonuclease activity $5^{\prime} \rightarrow 3^{\prime}$ of Taq DNA polymerase (16). qPCR reactions were performed in duplicate in MicroAmp ${ }^{\circledR}$ FastOptical 96-well plates, $0.1 \mathrm{ml}$ (Thermo Fisher Scientific, Inc.). A negative control was prepared by omission of target
DNA. The PCR reaction mixture with a final volume of $20 \mu 1$ contained $10 \mu 12 \mathrm{X}$ TaqMan ${ }^{\circledR}$ Genotyping Master Mix (Thermo Fisher Scientific, Inc.), $0.5 \mu 1$ 20X TaqMan Drug Metabolism SNP Genotyping Assay reagent Mix (Thermo Fisher Scientific, Inc.), $5.5 \mu \mathrm{l}$ ultra-pure water free of nucleases and $4.0 \mu \mathrm{l}$ target DNA. Thermocycling conditions were as follows: Initial denaturation for $10 \mathrm{~min}$ at $95^{\circ} \mathrm{C}$, followed by 50 cycles of denaturation for $15 \mathrm{sec}$ at $92^{\circ} \mathrm{C}$ and annealing/extension for $90 \mathrm{sec}$ at $60^{\circ} \mathrm{C}$ and post-PCR for $1 \mathrm{~min}$ at $60^{\circ} \mathrm{C}$. The device used for analysis was the 7500 Real-Time PCR System with inbuilt SDS 2.2 software for SNP genotyping (Thermo Fisher Scientific, Inc.).

The results were preliminarily analyzed using the complementary 7500 software version 2.5 (Applied Biosystems) of the PCR equipment and subsequently with TaqMan Genotyper software version 1.3 (Thermo Fisher Scientific, Inc.) for the calculation of the allelic frequency, as illustrated in Fig. 1 for variant CYP2D6*17.

Statistical analysis. For statistical analysis of the PCR results, Fisher's exact test was performed using Bioestat 5.3 software (Mamirauá Institute, Tefé, Brazil) and $\mathrm{P}<0.05$ was considered to indicate a statistically significant difference between groups.

\section{Results}

Allele frequency within the cohort. Genotyping of the 80 patients (Groups 1 and 2) showed that the CYP2D6*4, CYP2D6*10 and CYP2D6*17 alleles occurred in 11 (13.75\%), $17(21.25 \%)$ and eight patients (10\%), respectively (Table I).

Frequency of polymorphisms and phenotype metabolizers. Variant $* 4$ was present in 3 cases $(7.5 \%)$ in Group 1 and 8 $(20 \%)$ in Group 2. Furthermore, variant $* 10$ was present in 7 cases $(17.5 \%)$ from Group 1 and in $10(25 \%)$ from Group 2. Furthermore, variant $* 17$ was found in 4 patients (10\%) from each group. There was no statistical difference between the groups regarding the frequency of all polymorphisms, probably due to the low patient number $(\mathrm{P}=0.246)$. Regarding the metabolizer phenotype, normal metabolizers occurred in 37 $(92.5 \%)$ and in $33(82.5 \%)$ of patients from Groups 1 and 2, respectively. IM occurred in $2(5 \%)$ and $6(15 \%)$ patients from Groups 1 and 2, respectively, while null or poor metabolizers occurred in 1 individual $(2.5 \%)$ per group. There was no significant difference between the two groups regarding the frequency of all metabolizers, probably due to the low number of patients $(\mathrm{P}=0.789$; Table I).

\section{Discussion}

Studies on genetic polymorphisms are of great interest as they enhance the current understanding of the metabolism of numerous drugs, in particular anticancer drugs (17). This is particularly valid in Brazil due to the pronounced ethnic diversity and regional variability in miscegenation. The most commonly used endocrine therapy used for chemoprevention and adjuvant breast cancer treatment is the prodrug tamoxifen. Its efficacy depends on its metabolisation by the CYP2D6 enzyme into active metabolites, the major one being endoxifen. The gene encoding for CYP2D6 is highly polymorphic and 
the variants show a great diversity among different genotypes and populations (12).

In the present study, the most common allelic variant in the 80 patients assessed was the normal variant $* 1$, followed by variant $* 10$, which occurred in 7 patients from Group 1 and 10 from Group 2. Women in Group 1 (without recurrence) and 2 (with recurrence) showed the same frequency of poor metabolizers, while patients in Group 2 using tamoxifen showed a higher frequency of phenotypes of intermediate metabolizers compared to that in Group 1. However, differences between groups were not statistically significant, probably due to insufficient sample size.

The higher frequency of allelic variant $* 10$, which is pre-dominant in Asians but relatively rare in Caucasians (18), was not expected in the population from the northeast of Brazil assessed in the present study, which has a high level of ethnic miscegenation with a predominance of Afro-Brazilians. The CYP2D6 gene polymorphism encodes for an unstable protein, which leads to reduced activity of the CYP2D6 enzyme and is therefore classified as an intermediate metabolizer phenotype (19-21).

In the present study, no significant association between phenotypes of intermediate and null metabolizers with breast cancer recurrence was identified in a population of women from the Northeast of Brazil with hormone-sensitive breast cancer treated with tamoxifen. The lack of significance may be due to the small patient cohort. However, the results of the present study did not show any influence of the CYP2D6 gene polymorphisms $* 4, * 10$ and $* 17$ on the recurrence of breast cancer within the cohort. Of note, patients in Group 2 had a significantly higher frequency of axillary metastases than those in Group 1 and the lymph node status is a important prognostic factor and predictive of relapse. Although certain studies have shown that patients with the CYP2D6 gene polymorphisms $* 4, * 10$ and $* 17$ have more aggressive and tamoxifen-resistant hormone-sensitive breast cancer of a recurring nature, a lower overall survival and a lack of efficacy of tamoxifen treatment $(11,14,22)$, other studies have not shown any significant effect of CYP2D6 genotype variants on the risk of breast cancer recurrence in patients receiving adjuvant tamoxifen $(10,13)$, which is in agreement with the results of the present study. However, further studies with a larger sample size are required to identify a possible association of CYP2D6 gene polymorphisms with relapse of hormone-sensitive breast cancer in patients treated with adjuvant tamoxifen.

In conclusion, the present study showed that in a Northeast Brazilian population of hormone-sensitive breast cancer patients treated with tamoxifen, the CYP2D6*4, $* 10$ and $* 17$ gene polymorphisms were not significantly associated with disease recurrence. However, further studies using a larger population-based samples of patients with hormone-sensitive breast cancer should be performed to elucidate of the role of CYP2D6 gene polymorphism in the response to tamoxifen.

\section{Acknowledgements}

The authors would like to thank the Department of Mastology (Getulio Vargas Hospital, the Federal University of Piauí, Teresina, Brazil) and the Department of Oncology (Sao Marcos
Hospital Cancer Center, Teresina, Brazil) for their support in performing the present study.

\section{References}

1. Smith RA, Cokkinides V, Brooks D, Saslow D and Brawley OW: Cancer screening in the United States, 2010: A review of current American Cancer Society guidelines and issues in cancer screening. CA Cancer J Clin 60: 99-119, 2010.

2. International Agency for Cancer Research: Estimated Incidence, Mortality and Prevalence Worldwide in 2012. http://globocan. iarc.fr/old/FactSheets/cancers/breast-new.asp. Accessed February 16, 2016.

3. Parkin DM and Fernández LM: Use of statistics to assess the global burden of breast cancer. Breast J 12 (Suppl 1): S70-S80, 2006.

4. Jankowitz RC, McGuire KP and Davidson NE: Optimal systemic therapy for premenopausal women with hormone receptor-positive breast cancer. Breast 22 (Suppl 2): S165-S170, 2013.

5. Montemurro F, Del Mastro L, De Laurentiis M and Puglisi F: Endocrine therapy in premenopausal women with breast cancer: A critical appraisal of current evidence. Expert Rev Anticancer Ther 16: 211-218, 2016.

6. Howlader N, Chen VW, Ries LA, Loch MM, Lee R, DeSantis C, Lin CC, Ruhl J and Cronin KA: Overview of breast cancer collaborative stage data items - their definitions, quality, usage, and clinical implications: A review of SEER data for 2004-2010. Cancer 120 (Suppl 23): 3771-3780, 2014.

7. Hoskins JM, Carey LA and McLeod HL: CYP2D6 and tamoxifen: DNA matters in breast cancer. Nat Rev Cancer 9: 576-586, 2009.

8. Motamedi S, Majidzadeh K, Mazaheri M, Anbiaie R, Mortazavizadeh SM and Esmaeili R: Tamoxifen resistance and CYP2D6 copy numbers in breast cancer patients. Asian Pac J Cancer Prev 13: 6101-6104, 2012.

9. Kiyotani K, Mushiroda T, Sasa M, Bando Y, Sumitomo I, Hosono N, Kubo M, Nakamura Y and Zembutsu H: Impact of CYP2D6*10 on recurrence-free survival in breast cancer patients receiving adjuvant tamoxifen therapy. Cancer Sci 99: 995-999, 2008.

10. Morrow PK, Serna R, Broglio K, Pusztai L, Nikoloff DM, Hillman GR, Fontecha M, Li R, Michaud L, Hortobagyi G, et al: Effect of CYP2D6 polymorphisms on breast cancer recurrence. Cancer 118: 1221-1227, 2012.

11. Goetz MP, Knox SK, Suman VJ, Rae JM, Safgren SL, Ames MM, Visscher DW, Reynolds C, Couch FJ, Lingle WL, et al: The impact of cytochrome P450 2D6 metabolism in women receiving adjuvant tamoxifen. Breast Cancer Res Treat 101: 113-121, 2007.

12. van Schaik RH: Cancer treatment and pharmacogenetics of cytochrome P450 enzymes. Invest New Drugs 23: 513-522, 2005.

13. Martins DM, Vidal FC, Souza RD, Brusaca SA and Brito LM: Determination of CYP2D6 *3, *4, and *10 frequency in women with breast cancer in São Luís, Brazil, and its association with prognostic factors and disease-free survival. Braz J Med Biol Res 47: 1008-1015, 2014.

14. Schroth W, Antoniadou L, Fritz P, Schwab M, Muerdter T, Zanger UM, Simon W, Eichelbaum M and Brauch H: Breast cancer treatment outcome with adjuvant tamoxifen relative to patient CYP2D6 and CYP2C19 genotypes. J Clin Oncol 25: 5187-5193, 2007.

15. Karle J, Bolbrinker J, Vogl S, Kreutz R, Denkert C, Eucker J, Wischnewsky M, Possinger K and Regierer AC: Influence of CYP2D6-genotype on tamoxifen efficacy in advanced breast cancer. Breast Cancer Res Treat 139: 553-560, 2013.

16. De la Vega FM, Lazaruk KD, Rhodes MD and Wenz MH: Assessment of two flexible and compatible SNP genotyping platforms: TaqMan SNP Genotyping Assays and the SNPlex Genotyping System. Mutat Res 573: 111-135, 2005.

17. Abraham JE, Maranian MJ, Driver KE, Platte R, Kalmyrzaev B, Baynes C, Luccarini C, Shah M, Ingle S, Greenberg D, et al: CYP2D6 gene variants: Association with breast cancer specific survival in a cohort of breast cancer patients from the United Kingdom treated with adjuvant tamoxifen. Breast Cancer Res 12: R64, 2010.

18. Ingelman-Sundberg M: Genetic polymorphisms of cytochrome P450 2D6 (CYP2D6): Clinical consequences, evolutionary aspects and functional diversity. Pharmacogenomics J 5: 6-13, 2005. 
19. Fukuda T, Yamamoto I, Nishida Y, Zhou Q, Ohno M, Takada K and Azuma J: Effect of the CYP2D6*10 genotype on venlafaxine pharmacokinetics in healthy adult volunteers. Br J Clin Pharmacol 47: 450-453, 1999.

20. Goetz MP, Kamal A and Ames MM: Tamoxifen pharmacogenomics: The role of CYP2D6 as a predictor of drug response. Clin Pharmacol Ther 83: 160-166, 2008.

21. Toyama T, Yamashita H, Sugiura H, Kondo N, Iwase H and Fujii Y: No association between CYP2D6*10 genotype and survival of node-negative Japanese breast cancer patients receiving adjuvant tamoxifen treatment. Jpn J Clin Oncol 39: 651-656, 2009.
22. Irvin WJ Jr, Walko CM, Weck KE, Ibrahim JG, Chiu WK, Dees EC, Moore SG, Olajide OA, Graham ML, Canale ST, et al: Genotype-guided tamoxifen dosing increases active metabolite exposure in women with reduced CYP2D6 metabolism: A multicenter study. J Clin Oncol 29: 3232-3239, 2011. 